\title{
Effects of Chinaberry Tree Extract on Proliferation, Apoptosis, Migration and Cell Cycle Distribution of Human Breast Cancer Cells
}


www.ijpsonline.com

\section{JIAN, XIAO CHUNHONG ${ }^{1 *}$, C. HONGYAN, LU HUIJUN, YU HAIZHONG* AND Y. JIANFEN}

Department of Clinical Laboratory, Affiliated Traditional Chinese Medicine Hospital of Nantong University, Nantong, Jiangsu, P.R. China, ${ }^{1}$ Department of Clinical Laboratory, Nantong Tumor Hospital, Nantong, Jiangsu, P.R. China

Jian, et al.: Effects of Chinaberry Tree Extract on Breast Cancer Cells

To study the effects of chinaberry tree extract on proliferation, apoptosis, migration and cell cycle distribution of human breast cancer cells, the MCF-7 breast cancer cells obtained were divided into blank group, low concentration group, medium concentration group and high concentration group. Phosphate buffered saline solution and sterile physiological saline were added to the blank group for cell culture. 3-(4,5-Dimethylthiazol-2-yl)-2,5-diphenyltetrazolium bromide and flow cytometry were used to detect cell proliferation and apoptosis at different time periods. Transwell assay was used to detect cell migration; flow cytometry was used to detect cell cycle distribution, and intercellular cell adhesion molecule-1, matrix metalloproteinase-2, matrix metalloproteinase-9 were detected by Western blotting. The proliferation rate of MCF-7 breast cancer cells in the low, medium and high concentration group was significantly lower than that in the blank group at different time periods, while the apoptosis rate was significantly higher than that in the blank group, and the effect was more obvious with the increase of concentration $(p<0.05)$. The number of cell migration of MCF-7 breast cancer cells in the low, medium and high concentration group was significantly reduced compared with the blank group, and the cell migration was significantly reduced with the increase of the extract concentration of chinaberry tree $(p<0.05)$. The higher the extract concentration of chinaberry tree, the lower the proportion of MCF-7 cells in G0/G1 and S cycle and the higher the proportion of MCF-7 cells in G2/M cycle $(\mathbf{p}<\mathbf{0 . 0 5})$. The expressions of intercellular cell adhesion molecule-1, matrix metalloproteinase-2 and matrix metalloproteinase-9 in the low, medium and high concentration groups were significantly lower than those in the blank group, and the expressions of intercellular cell adhesion molecule-1, matrix metalloproteinase-2 and matrix metalloproteinase-9 in the high concentration group were significantly lower than those in the low and medium concentration groups $(\mathbf{p}<0.05)$. The extract of chinaberry tree can effectively inhibit the proliferation and migration promote the apoptosis and reduce the growth of breast cancer cells by changing the periodic distribution of cancer cells, and its ability is concentration dependent.

Key words: Extract of chinaberry tree, human breast cancer cells, cell cycle, matrix metalloproteinase

Breast cancer, one type of common malignant tumor, has high incidence rates that recently tend to make the average age of patients shorter, seriously affecting people's life and health ${ }^{[1,2]}$. Chemotherapy is usually used for treatment of such diseases, but chemotherapeutics produce toxic and side effects and patients are prone to be tolerant to them besides. As a result, finding native compounds that are derived from plants has been a hotspot in the medical field ${ }^{[3,4]}$. Szechwan Chinaberry extracts, just as its name implies, are triterpenoids extracted from Szechwan Chinaberry which is a type of plants in Meliaceae. Studies have shown that Szechwan Chinaberry extracts impose inhibiting effects on various tumor cells $\mathrm{s}^{[5]}$. However, the mechanism of inhibition of such extracts to breast cancer cells was rarely studied, let alone the roles of different concentrations of extracts in these activities. In this paper, the breast cancer cells were treated with various concentrations of Szechwan Chinaberry extracts to find any changes in cell proliferation, apoptosis, migration and cycles in the hope of indicating the inhibition of Szechwan Chinaberry extracts with different concentrations on breast cancer cells.

The cell line used in this study was MCF-7 human breast cancer cells purchased from Tumor Cell Repository of the Chinese Academy of Medical Sciences. This research was approved by the Ethics Committee of the Affiliated Traditional Chinese Medicine Hospital of Nantong University. The following are the test articles and reagents used with their sources indicated. Szechwan Chinaberry extracts (Tianzen Biotech, Beijing Co., Ltd.), mouse antihuman intercellular cell adhesion molecule-1 (ICAM-1) antibody (Zoonbio Biotechnology Co., Ltd.), mouse antihuman matrix metalloproteinase-2 (MMP-2) and MMP-9 monoclonal antibody, MTT and Transwell Kits (Boster Biological Technology Co., Ltd.), and PBS buffer (ZSGB-BIO).

The cryopreserved MCF-7 human breast cancer cells were shaken to dissolution in $40^{\circ}$ water bath once 
these were fetched out. The temperature $40^{\circ}$ was maintained with the help of a digital water bath $(\mathrm{BH}$ series precision). Then $2 \mathrm{ml}$ of medium (10\% PBS, $1 \%$ of $500 \mathrm{ml}$ double-antibody mycillin and RPMI1640 medium) was added followed by centrifugation at $1000 \mathrm{rpm}$ for $5 \mathrm{~min}$. The supernatant was discarded. Cells were resuspended in complete medium before they were transferred to culture flasks for sub culturing with $5 \mathrm{ml}$ of the medium. These cells were placed in a $\mathrm{CO}_{2}$ incubator $\left(37^{\circ}\right.$, saturated humidity 95:5 \% $\mathrm{CO}_{2}$ ) and on the next day, as the cellular fusion rate was up to $80-90 \%$ the cells were treated for continuous passage. MCF-7 human breast cancer cells used were divided into the control group, low concentration group, moderate concentration group and high concentration group. Twenty four hours after the inoculation, the medium was replaced by serum-free medium accompanied with the addition of Szechwan Chinaberry extracts for pretreatment for $24 \mathrm{~h}$. Later, the cells were being starved for another $24 \mathrm{~h}$ before the medium was replaced by serum-free media. On daily basis, Szechwan Chinaberry extracts were applied followed by extraction of cellular proteins $48 \mathrm{~h}$ after. Within a total of 4 wells, $1 \mu \mathrm{l}$ of PBS solution, and sterile saline solution, 25, 50 and $75 \mathrm{nM}$ Szechwan Chinaberry extracts were placed respectively for cultivation.

The prepared cell suspension using the cultured cells above was added into wells of a 96-well plate, $90 \mu 1$ each. The observation points for cells in the control, low, moderate and high concentration groups were at $12,24,36,48,60$ and $72 \mathrm{~h}$ after the injection. Five replicate wells were set aside for each group to be added with different concentrations of Szechwan Chinaberry extracts. Cells of the control group were treated in each well with $10 \mu \mathrm{l}$ of the culture medium and then cultivated for the same temporal periods as that in groups subjected to 3 different concentrations of extracts. Once the time was up, $20 \mu \mathrm{l}$ of MTT was added into each well for 4-h incubation. Then, as the supernatant in wells was absorbed, $150 \mu \mathrm{l}$ of DMSO was added followed by shaking for $10 \mathrm{~s}$. The OD values of groups at $570 \mathrm{~mm}$ were measured in a microplate reader. The proliferation rates of MCF-7 human breast cancer cells were calculated using the following formula, $\%$ proliferation rate $=(\mathrm{OD}$ value $/$ reference value-1) $\times 100$.

Cells of the 4 groups were placed into a 5-well plate for cultivation at $37^{\circ}, \mathrm{CO}_{2}$ concentration of $5 \%$ with saturated humidity, within $12,24,36,48,60$ and
$72 \mathrm{~h}$ respectively, before $0.25 \%$ of trypsin solution was added for digestion. Later, the cells were collected by centrifugation at $2000 \mathrm{rpm}$ for $5 \mathrm{~min}$ and washed with PBS buffer twice for 3 min each time. Once again, centrifugation at $2000 \mathrm{rpm}$ was applied to separate cells which were collected and dissolved in $1 \mathrm{ml}$ of PI staining solution, placed aside for $1 \mathrm{~h}$ in the dark at room temperature. Once being labeled with specific fluorescence, the cells surrounded by rapidly flowing sheath fluids emitted photons which may be detected by a flow cytometer in terms of the photon numbers. The apoptosis was in this way measured and the technique used was the TUNEL technique (Volker, Cancer letters 1949:1;125-131,2003).

Breast cancer cells in the logarithmic phase were treated into a cell density of $3 \times 10^{5}$ cells $/ \mathrm{ml}$ before they were resuspended in blood serum medium of $1 \%$. In each chamber $100 \mu \mathrm{l}$ of the cell suspension prepared was injected, and the Transwell chambers was placed on the culture plate followed by the addition of serumfree medium, set aside for 30 min until the completion of matrigel rehydration. After $24 \mathrm{~h}$ of cultivation with the cell suspension prepared and blood serum medium in saturated humid environment, the cells in chambers were washed with PBS buffer and fixed by paraformaldehyde and then subjected to crystal violet staining for $15 \mathrm{~min}$ in each group. Once again, PBS buffer was used to rinse the cells 3 times. Finally, 5 fields randomly selected were photographed under the microscope to count the number of cells, which shall be repeated 3 times in each group.

Seventy two hours after the cultivation in various concentrations of Szechwan Chinaberry extracts, MCF-7 cells were collected and $1 \mathrm{ml}$ of $1 \%$ ethanol solution was added for immobilization at $4^{\circ}$ overnight. PI $(50 \mu \mathrm{g} / \mathrm{ml})$ was used to stain, before the incubation in dark for $0.5 \mathrm{~h}$ at $4^{\circ}$. The distribution of cell cycles was detected using the flow cytometer.

The collected samples were rinsed 3 times with PBS buffer, which was then separated out, and applied with IP cell lysate for $35 \mathrm{~min}$ before the total proteins were extracted and determined by bicinchoninic acid assay (BCA method). At a density of $20 \mu \mathrm{g} / \mathrm{well}$, the collected proteins that have been treated with concentrated SDSPAGE sample loading buffer for 15 min were subjected to SDS-PAGE gel electrophoresis at $100 \mathrm{~V}, 10 \mathrm{~min}$. Later, the membrane was soaked in $10 \%$ milk and sealed on the shaking table at $37^{\circ}, 1.5 \mathrm{~h}$. TBST was used to dilute the primary antibody $\beta$-actin (internal 
control) at a ratio of 1:1000. In combination with the primary antibody, the membrane was incubated at $4^{\circ}$ overnight and stored. On the next day, it was rinsed with a TBST buffer and treated with the second antibody for incubation within $1 \mathrm{~h}$, followed by repeated rinsing in TBST buffer. At the end, following the instructions of developing and fixing kit, the developing agent was applied for substrate coloring.

SPSS21.0 statistical software was used for data analysis. Measurement data were expressed in mean \pm standard deviation (SD). In terms of comparison among multiple groups, $F$ tests were adopted. As to pairwise comparison, independent t-test shall be used. $\mathrm{P}<0.05$ was considered as statistical significance.

The proliferation rates of breast cancer cells in the low, moderate and high concentration group as detected at different temporal points were significantly lower than those in the control group, and the rates in the high concentration group inferior to those in the low concentration group, with the differences statistically significant $(\mathrm{p}<0.05)$, as shown in fig. 1 .

The apoptosis rate of cells in the low, moderate and high concentration group as detected at different temporal points were obviously greater than those in the control group, in addition to the rates in the high concentration group superior to those in the low concentration group. The differences were statistically significant $(p<0.05)$, as shown in fig. 2 .

As it can be seen from fig. 3, the number of migrated cells in the low, moderate and high concentration group notably decreased as compared to that in the control group. Actually, the number of migrated cells decreased with the increase of concentration of Szechwan Chinaberry extracts.

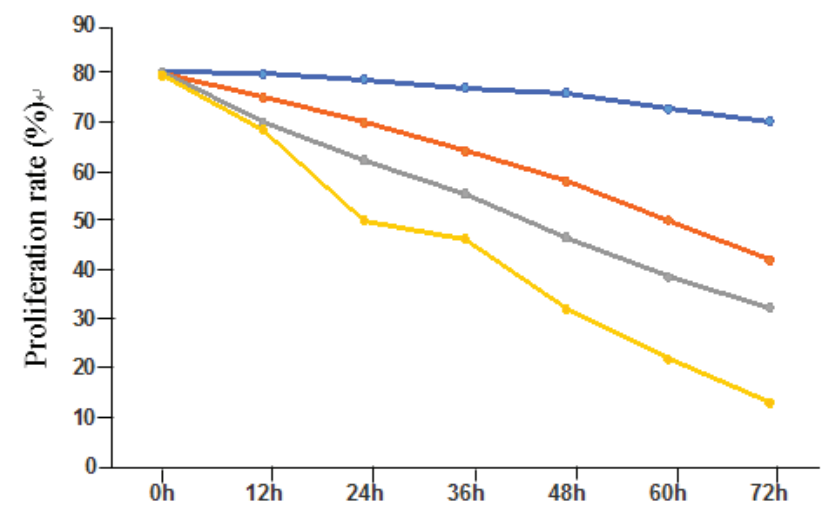

Fig. 1: Proliferation of breast cancer cells Proliferation of breast cancer cells at different time points under different concentrations of Szechwan Chinaberry extracts. $(-\bullet-)$ Control group, $(-\bullet-)$ low dose group, $(-\bullet-)$ middle dose group, (-०) high dose group

18
Fig. 4 showed that the proportion of cells in $\mathrm{G}_{0} / \mathrm{G}_{1}$ and $\mathrm{S}$ period decreased significantly, while those in $\mathrm{G}_{2} / \mathrm{M}$ period increased notably, with the increase of concentration of Szechwan Chinaberry extracts. The differences revealed statistical significance as well $(\mathrm{p}<0.05)$.

With the intervention of Szechwan Chinaberry extracts at different concentrations, the expressions of ICAM-1, MMP-2 and MMP-9 in cells of the 3 groups obviously decreased as compared to those in the control one $(p<0.05)$, and the levels of the high concentration group were lower than that of the low or moderate concentration group $(\mathrm{p}<0.05)$, as shown in fig. 5 .

At present, the therapy of breast cancer included operation, radiotherapy, chemotherapy, endocrinotherapy and targeted therapy ${ }^{[5,6]}$, among which the operative treatments, although they are usually the preferred choice, may be denied by most female patients because this affects body aesthetics ${ }^{[7-9]}$. Treatment for cancers with plant extracts has been a hotspot in the medical field. Given the single monomeric composition of plant extracts, those anticancer components can be easily separated and purified, with respect to breast cancer, would inhibit cancer growth in a more scientific and accurate way ${ }^{[10,11]}$. In this investigation, MCF-7 human breast cancer cells were treated with Szechwan Chinaberry extracts, followed by detection of cell proliferation, apoptosis, migration and cyclic distribution using MTT assay, immunofluorescence, trans well assay and flow cytometry respectively, so as to determine the intervening effects of the extracts on these cells and their clinical applications.

Szechwan Chinaberry extracts contain triterpenoids with certain toxicity that at the earliest used in agricultural desensitization. They have been applied as an anthelmintic for more than $50 \mathrm{y}$ actually ${ }^{[12-14]}$. Studies showed that Szechwan Chinaberry extracts exhibited biological activities in blocking neuromuscular junctions, antibotulism, and affecting efferent nerves, central nervous and the respiratory system ${ }^{[15-17]}$. Recently, several experts and scholars pointed out that Szechwan Chinaberry extracts have antineoplastic effects, including inhibition to hepatocellular carcinoma cells, human leukemia cells and human breast cancer cells, by primarily inducing the apoptosis of relevant cells ${ }^{[18-20]}$. In this paper, the Szechwan Chinaberry extracts were added at 25, 50 and $75 \mathrm{nM}$ concentrations to MCF-7 cells. The cells in the control group were exposed to saline solution. After being 

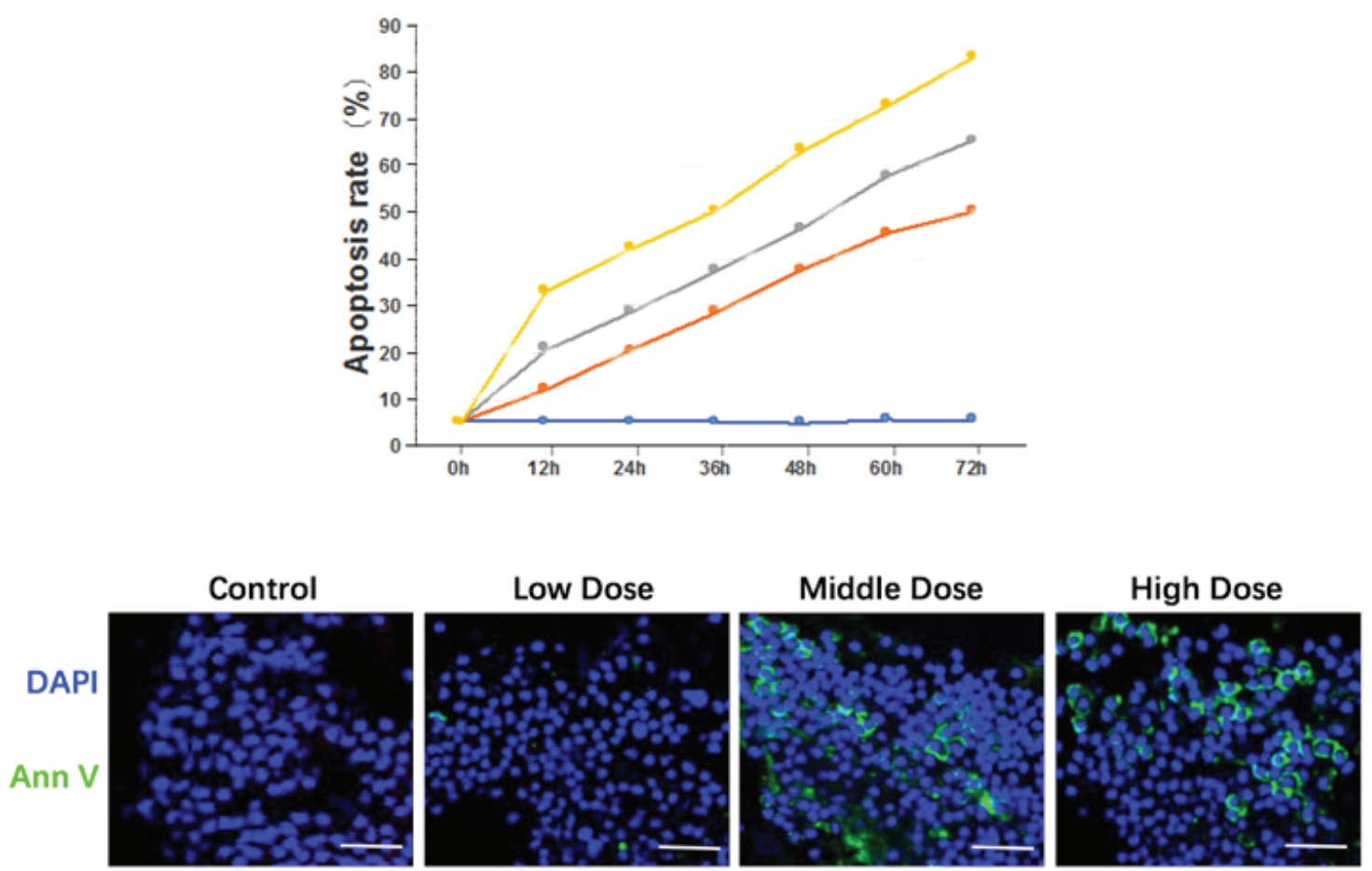

Fig. 2: Apoptosis of breast cancer cells

Apoptosis of breast cancer cells at different time points under different concentrations of Szechwan Chinaberry extracts. $(-\bullet-)$ Control group, $(-\bullet-)$ low dose group, $(-\bullet-)$ middle dose group, $(-\bullet-)$ high dose group

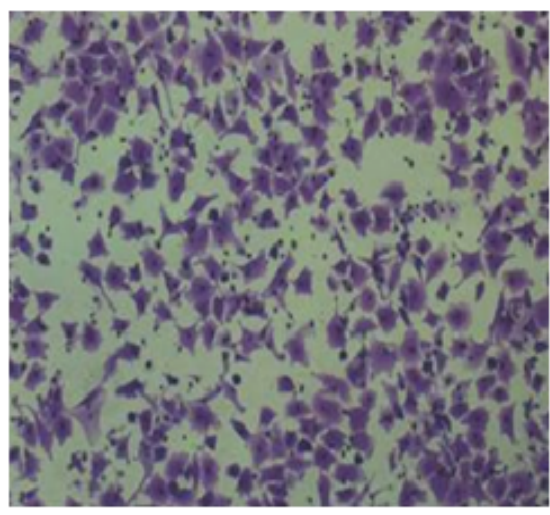

A

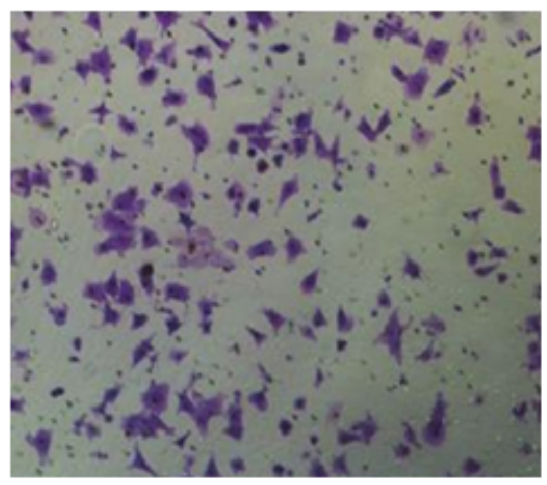

C

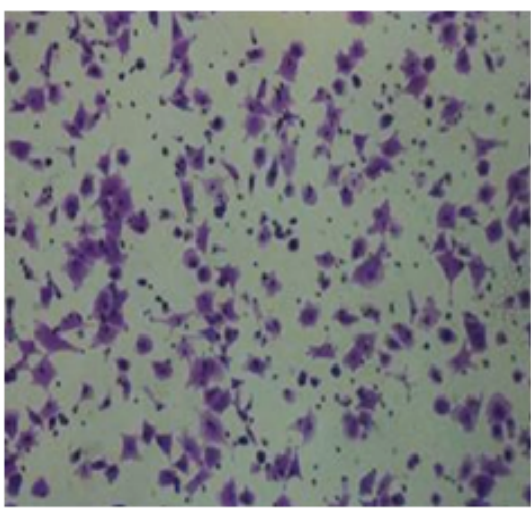

B

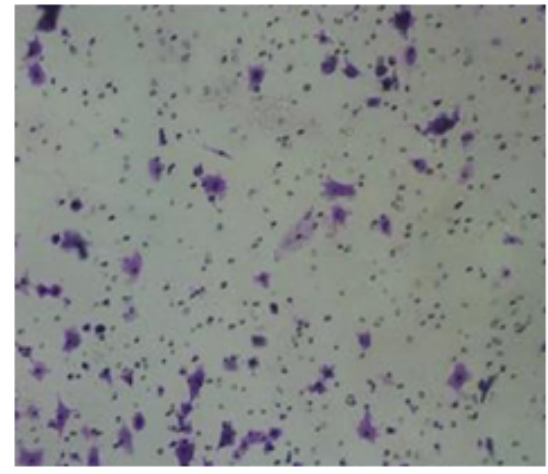

D

Fig. 3: Migration of breast cancer cells

The migration of breast cancer cells under different concentrations of Szechwan Chinaberry extracts. Methylrosanilnium chloride solution $\times 100$, (A) control group, (B) low dose group, (C) middle dose group, (D) high dose group 
cultivated for a certain period at 6 temporal points, these cells were detected in terms of proliferation and apoptosis using MTT and immunofluorescence assays. As the results showed, the proliferation rate of breast cancer cells decreased with time. The falling range in the control group was not as apparent as good, but the proliferation rates in the other groups exposed to Szechwan Chinaberry extracts have significantly decreased, indicating the Szechwan Chinaberry extracts exerted inhibitory effect on breast cancer cells. Besides, this was supported by the results of apoptosis experiment where the apoptotic rates of cells treated with the Szechwan Chinaberry extracts at 3 different concentrations were obviously increased. It also found that the inhibiting forces imposed on cells applied with the high concentration of Szechwan Chinaberry extracts were much more powerful than that in the low or moderate concentration group, in addition to the notably increased apoptotic rates. These suggested the Szechwan Chinaberry extracts inhibit breast cancer cells in a concentration-dependent way. The higher the concentration, the more obvious is the inhibition.

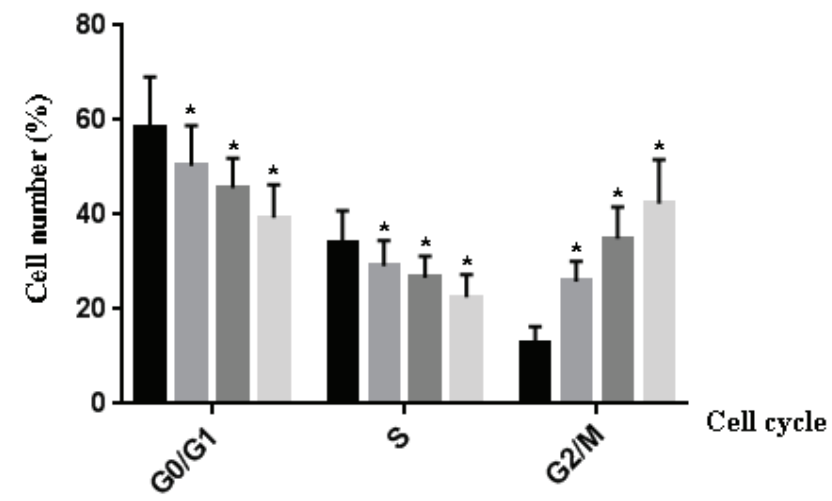

Fig. 4: Cell cycle distribution of breast cancer cells Effects of different concentrations of Szechwan Chinaberry extracts on cell cycle distribution of breast cancer cells. (घ) Blank group, ( $\square$ ) low concentration group, ( $\square$ ) medium concentration group, $(\square)$ high concentration group
Transwell assays were applied to determine the migration of breast cancer cells. As the results showed, different concentrations of extracts produced varied migration effects. The maximum of migrated cells was observed in the control group, while the minimum found in the high concentration group, indicating some blocking effects on the migration of breast cancer cells by the Szechwan Chinaberry extracts. In terms of cyclic distribution, with the intervention of Szechwan Chinaberry extracts, the proportion of cells in $\mathrm{G}_{0} / \mathrm{G}_{1}$ and $\mathrm{S}$ period markedly decreased and the proportion of cells in $\mathrm{G}_{2} / \mathrm{M}$ period increased. These results revealed that the inhibition of Szechwan Chinaberry extracts on breast cancer cells may also be realized by altering the distribution of cell cycles.

Studies have pointed out that tumor metastasis, by which the tumor cells break away from their own cell population to a new organ where they form new tumors, has made the planned therapeutic regime more difficult to implement. Control of metastasis therefore has been an effective method for cancer treatment ${ }^{[21]}$. ICAM-1, the member of immunoglobulin superfamily, is one kind of important surface adhesion molecules. They were rarely expressed or even never expressed in normal tissues, unlike the over-expression of them in malignant tumors, which may indicate that ICAM-1 plays some important roles in the metastasis of breast cancer cells ${ }^{[22-24]}$. MMPs are membrane-binding proteins that degrade extracellular matrix and show vital functions in promoting cancer metastasis ${ }^{[25-27]}$. As some experts revealed, MMP-2 and MMP-9 function well in invasion and metastasis of breast cancer cells. During any metastasis, the breast cancer cells must go through the basal membrane in the vascular walls, which means that an elevated expression level of MMP-2 and MMP-9 indicates certain diffusion and metastasis of tumor cells ${ }^{[28-30]}$. In this paper, it was found the level of

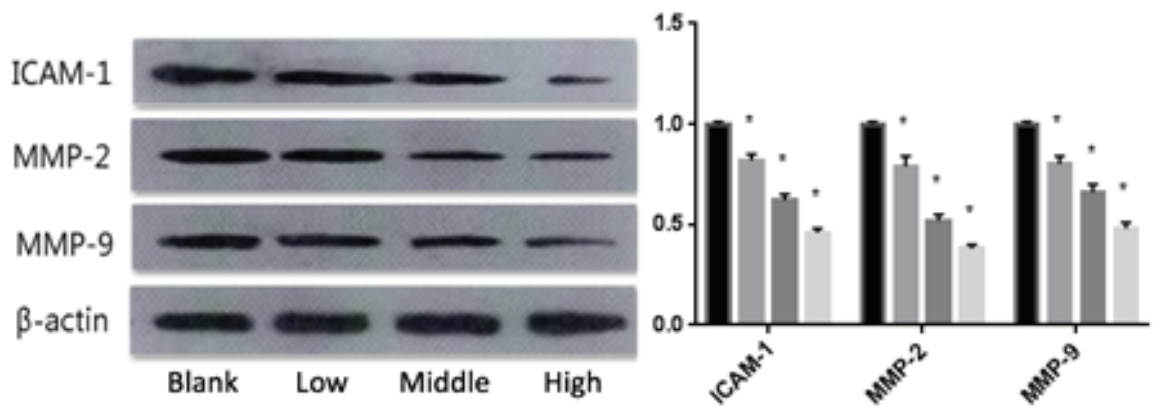

Fig. 5: ICAM-1, MMP-2 and MMP-9 protein expression

Effects of Szechwan Chinaberry extracts on ICAM-1, MMP-2 and MMP-9 protein expression. ( $\square$ ) Blank group, ( $\square$ ) low concentration group, ( $\square$ ) medium concentration group, $(\square)$ high concentration group 
expressions of ICAM-1, MMP-2 and MMP-9 in breast cancer cells treated with Szechwan Chinaberry extracts significantly decreased. This told that the inhibition of Szechwan Chinaberry extracts to metastasis of breast cancer cells may be realized by regulation of ICAM-1, MMP-2 and MMP-9 expressions.

In conclusion, the Szechwan Chinaberry extracts effectively inhibited the proliferation and migration of breast cancer cells in a concentration-dependent manner by changing the distribution of cell cycles, in addition promoted the apoptosis of tumor cells. The research in this paper shall provide vital theoretical basis for future treatment of breast cancers.

\section{Conflict of interest:}

No conflict of interest between any of the authors.

\section{REFERENCES}

1. Ghoncheh M, Pournamdar Z, Salehiniya H. Incidence and mortality and epidemiology of breast cancer in the world. Asian Pac J Cancer Prev 2016;17:43-6.

2. Sitlinger A, Shelby RA, Van Denburg AN, White H, Edmond $\mathrm{SN}$, Marcom PK, et al. Higher symptom burden is associated with lower function in women taking adjuvant endocrine therapy for breast cancer. Geriatr Oncol 2019;10:317-21.

3. Gali-Muhtasib H, Hmadi R, Kareh M, Tohme R, Darwiche N. Cell death mechanisms of plant-derived anticancer drugs: beyond apoptosis. Apoptosis 2015;20:1531-62.

4. Shi H, Liu J, Tu Y, Freter CE, Huang C. Oolong tea extract induces DNA damage and cleavage and inhibits breast cancer cell growth and tumorigenesis. Anticancer Res 2018,38:6217-23.

5. Nagini S. Breast cancer: current molecular therapeutic targets and new players. Anticancer Agents Med Chem 2017;17: 152-63.

6. Henry D, von Moos R, Body JJ, Rider A, De Courcy J, Bhowmik D, et al. Bone-targeted agent treatment patterns and the impact of bone metastases on patients with advanced breast cancer in the United States. Curr Med Res Opin 2019;14:1-16.

7. Kim E, Andersen MR, Standish LJ. Comparison of healthrelated quality of life between adjuvant breast cancer treatment groups. Oncol Nurs Forum 2019;46:59-70.

8. Liu J, Guo W, Tong M. Intraoperative indocyanine green fluorescence guidance for excision of nonpalpable breast cancer. World J Surg Oncol 2016;14:266.

9. Biehler-Gomez L, Giordano G, Cattaneo C. The appearance of breast cancer metastases on dry bone: Implications for forensic anthropology. Forensic Leg Med 2019;61:5-12.

10. Baraya YS, Wong KK, Yaacob NS. The immunomodulatory potential of selected bioactive plant-based compounds in breast cancer: a review. Anticancer Agents Med Chem 2017; 17:770-83.

11. Lazzeroni M, Guerrieri-Gonzaga A, Gandini S, Johansson H, Serrano D, Cazzaniga M, et al. A presurgical study of lecithin formulation of green tea extract in women with early breast cancer. Cancer Prev Res 2017;10:363-70.

12. Mustafa M. Antibacterial efficacy of neem (Azadirachta indica) extract against enterococcus faecalis: an in vitro study. J Contemp Dent Pract 2016;17:791-4.
13. Wu Q, Kohli M, Bergen HR 3rd, Cheville JC, Karnes RJ, $\mathrm{Cao} \mathrm{H}$, et al. Preclinical evaluation of the supercritical extract of Azadirachta indica (neem) leaves in vitro and in vivo on inhibition of prostate cancer tumor growth. Mol Cancer Ther 2014;13:1067-77.

14. Pei Z, Fu W, Wang G. A natural product too sendanin inhibits epithelial-mesenchymal transition and tumor growth in pancreatic cancer via deactivating Akt/mTOR signaling. Biochem Biophys Res Commun 2017;493:455-60.

15. Quelemes PV, Perfeito ML, Guimarães MA, dos Santos RC, Lima DF, Nascimento C, et al. Effect of neem (Azadirachta indica A. Juss) leaf extract on resistant Staphylococcus aureus biofilm formation and Schistosoma mansoni worms. J Ethnopharmacol 2015;175:287-94.

16. Kai W, Yating S, Lin M, Kaiyong Y, Baojin H, Wu Y, et al. Natural product toosendanin reverses the resistance of human breast cancer cells to adriamycin as a novel PI3K inhibitor. Biochem Pharmacol 2018;152:153-64.

17. Zheng MD, Wang ND, Li XL, Yan J, Tang JH, Zhao XH, et al. Toosendanin mediates cisplatin sensitization through targeting Annexin A4/ATP7A in non-small cell lung cancer cells. Nat Med 2018;72:724-33.

18. Zhou Q, Wu X, Wen C, Wang H, Wang H, Liu H, et al. Toosendanin induces caspase-dependent apoptosis through the p38 MAPK pathway in human gastric cancer cells. Biochem Biophys Res Commun 2018;505:261-6.

19. Arumugam A, Agullo P, Boopalan T, Nandy S, Lopez $\mathrm{R}$, Gutierrez, et al. Neem leaf extract inhibits mammary carcinogenesis by altering cell proliferation, apoptosis, and angiogenesis. Cancer Biol Ther 2014;15:26-34.

20. Zhang S, Cao L, Wang ZR, Li Z, Ma J. Anti-cancer effect of toosendanin and its underlying mechanisms. Asian Nat Prod Res 2019;21:270-83.

21. Alečković M, Kang Y. Regulation of cancer metastasis by cell-free miRNAs. Biochim Biophys Acta 2015;1855:24-42.

22. Kang JH, Choi MY, Cui YH, Kaushik N, Uddin N, Yoo KC, et al. Regulation of FBXO4-mediated ICAM-1 protein stability in metastatic breast cancer. Oncotarget 2017;8:83100-13.

23. Kwon KM, Chung TW, Kwak CH, Choi HJ, Kim KW, Ha SH, et al. Disialyl GD2 ganglioside suppresses ICAM-1-mediated invasiveness in human breast cancer MDA-MB231 cells. Int J Biol Sci 2017;13:265-75.

24. Guo P, Yang J, Jia D, Moses MA, Auguste DT. ICAM-1Targeted, Lcn2 siRNA-Encapsulating Liposomes are Potent Anti-angiogenic Agents for Triple Negative Breast Cancer. Theranostics 2016;6:1-13.

25. Puzovic V, Brcic I, Ranogajec I, Jakic-Razumovic J. Prognostic values of ETS-1, MMP-2 and MMP-9 expression and co-expression in breast cancer patients. Neoplasma 2014;61:439-46.

26. Merdad A, Karim S, Schulten HJ, Dallol A, Buhmeida A, AlThubaity F, et al. Expression of matrix metalloproteinases (MMPs) in primary human breast cancer: MMP-9 as a potential biomarker for cancer invasion and metastasis. Anticancer Res 2014;34:1355-66.

27. Yun EJ, Song KS, Shin S, Kim S, Heo JY, Kweon GR, et al. Docosahexaenoic acid suppresses breast cancer cell metastasis by targeting matrix-metalloproteinases. Oncotarget 2016;7:49961-71.

28. Xu H, Li M, Zhou Y, Wang F, Li X, Wang L, et al. S100A4 participates in epithelial-mesenchymal transition in breast cancer via targeting MMP2. Tumour Biol 2016;37:2925-32. 
www.ijpsonline.com

29. Abdelmawgoud H, El Awady RR. Effect of Sirtuin 1 inhibition on matrix metalloproteinase 2 and Forkhead box O3a expression in breast cancer cells. Genes Dis 2017;4:240-6.

30. Reggiani F, Labanca V, Mancuso P, Rabascio C, Talarico G, Orecchioni $\mathrm{S}$, et al. Adipose Progenitor Cell Secretion of GM-CSF and MMP9 Promotes a Stromal and Immunological Microenvironment That Supports Breast Cancer Progression. Cancer Res 2017;77:5169-82.
This is an open access article distributed under the terms of the Creative Commons Attribution-NonCommercial-ShareAlike 3.0 License, which allows others to remix, tweak, and build upon the work non-commercially, as long as the author is credited and the new creations are licensed under the identical terms

This article was originally published in a special issue, "XXXXXX"

Indian J Pharm Sci 2020:82(1)spl issue1; XX-XX 